Ankara Ecz. Fak. Mec.

7. 67 (1977) j. Fac. Pharm Ankara

7. 67 (1977)

\title{
Thuja orientalis L. Uçucu Yă̆ı Üzerinde Araştırmalar
}

\author{
Researches on the Volatile Oil of Thuja orientalis L.
}

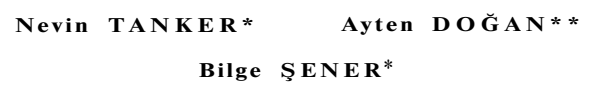

Yurdumuzda "Mazı" adı altında bilinen Thuja orientalis L. (Cupressaceae), parklarda, bahçelerde daha çok çit yapmak amacıyla yetiştirilen bir bitkidir. Dalları yelpaze biçiminde, tohumları kanatsız olan ve kurak yerlerde de yetişen bu bitkinin ana vatanı Hindistandır. Çin'de ve Japonya'da yaygın biçimde ratlanan bu bitkinin Hindistan'a, çok yıllar önce Çin ve Japonya'dan gelmiş olması büyük bir olasidir (1).

T. orientalis'in kök (1), meyva (2), odun (3) ve tohumundan (4) elde edilen yağlar üzerinde yapılmış çalışmalar vardır. Hatta Azerbaycan'da kültürü yapılan bitkinin yapraklarında bulunan uçucu yağ üzerinde de araştırma yapılmıştır (5), ancak, gaz kromatografisi yöntemi uygulanmamıştır.

Biz bu çalışmada Anadolu'nun iki ayrı yöresinden ve değişik iklimlerde toplanan genç dal ve yapraklardan elde edilen uçucu yağ fizikokimyasal özelikleri ve içerdiği etken maddeleri açısından incelemeyi amaçladık. Özellikle, içerdiği maddelerin saptanmasında, bu yağlarda uygulanmamış olan sütun ve gaz kromatografisi yöntemlerini kullandik.

Mazı uçucu yağı, eskiden, dışardan tahrişe karşı, içeriden de kalbi uyarıcı olarak uygulanmıştır. Bu gün için hiç bir ilâcın hazırlan-

Redaksiyona verildiği tarih: 21 Nisan 1977

* Farmakognozi ve Farmasötik Botanik Kürsüsü, Eczacılık Fakültesi, Ankara Üniversitesi.

* Gıda Bilimi ve Teknolojisi Kürsüsü, Ziraat Fakültesi, Ankara Üniversitesi 
masında yer almamakta ise de oda spreylerinin, deodoranların ve teknik müstahzarların kokulandırılması için, çam ve sedir yağı ile karışık olarak kullanılmaktadır.

T. occidentalis üzerinde yapılmış çalışmalara göre, yapraklardan subuharı distilasyonuyla elde edilen uçucu yağ verimi, birçok faktöre bağlı olarak değişmektedir. Mevsim (şubat ve mart aylarında en yüksek, hazirandan eylüle kadar en düşük), ağacın yaşı (genç ağaçlarda verim daha yüksek), güneş alma durumu (güneşli yerlerde yetişenlerde verim yüksek) bu etkenler arasında sayılabilir (6).

MATERYAL ve YÖNTEM

Thuja orientalis dalları, Ankara'da, A. ü. Ziraat Fakültesi deneme bahçesi etrafındaki çitlerden, 1974 Ağustos ve 1977 Ocak aylarında; Mersinden ise 1975 yılı A ğustos ayında toplanmıştır.

1-2 gün havada kurutulmuş yapraklı yeşil dallar, küçük parçalara ayrılarak bakır bir imbiğe yerleştirilmiş ve subuharı distilasyonu uygulanmıştır.

Elde edilen uçucu yağın fizikokimyasal özelikleri ve indeksleri klasik yöntemlerle saptandıktan sonra, yağın bileşimindeki maddelerin analizi için ve gaz kromatografa uygulanmak üzere fraksiyonlarına ayrild1.

Bundan önceki çalışmalarımızda da uyguladı̆̆ımız gibi, yă̆ önce silikagel sütun üzerinde, n-pentan ile yıkanarak monoterpenik hidrokarbürleri ayrıldı. Kolonda kalan oksijenli monoterpenler ise etil asetat ile kazanıldi (7).

Gaz kromatografik analizde \% 10 PEG 20M kolonundan yararlanıldı. Burada, Jüniperus nana Willd. yapraklan ile çalışmada iyi sonuç alınan sistem ve koşullar uygulandı (8), kolon ısısı başlangıçta $70^{\circ} \mathrm{C}$ de tutularak monoterpenik hidrokarbürlerin kromatogram 1 alındı. Thuja yağlarında varlığı bilinen tuyon, fenkon, karyofillen gibi maddelerin incelenmesi için de kolon 1 sısı $150^{\circ} \mathrm{C}$ ye kadar yükseltildi.

Gaz kromatogramlarda belirlenen piklerin tanınması, aynı koşullarda analizi yapılmış uçucu yağ ile karşılaştırılarak ve ayrıca saf maddelerden yararlanarak gerçekleştirilmiştir. Miktarların saptanması, planimetre ile ölçerek hesaplanmıştır. 


\section{B U L G U L A R}

Thuja orientalis yapraklarında bulunan uçucu yağın miktar tayini, volumetrik olarak, C LEVEN GER apareyinde yapıldı. Bulunan uçucu yă̆ miktarları aşağıdaki tabloda (I) gösterilmiştir.

Tablo I. T. orientalis'te su miktarı ve kuru örneklerde Uçucu yă verimleri

Su \%

Ankara, ağustos (1974)

Ankara, ocak (1977)

Mersin, ağustos (1975)
52

50.4

52
Uçucu yă̆ \%

0.84

0.79

1.66

Susuz sodyum sülfat üzerinde kurutulmuş uçucu yağın rengi sarımsı olup kâfura benzer hafif kokuludur.

Uçucu yağın saptanan fizikokimyasal özelikleri şöyledir:

\author{
Spesifik ağırlık, $20^{\circ} \mathbf{G}$ \\ Optik çevirme \\ Kirılma indeksi \\ \% 70 lik etanolde çözünürlük \\ Asitlik indeksi \\ Ester indeksi \\ Sabunlaşma indeksi
}

\begin{tabular}{ccc} 
Ank. Ă̆ustos & Ank. ocak & Mer.ağustos \\
\hline 0.9118 & 0.8738 & 0.8706 \\
$-11^{\circ} .4$ & $-11^{\circ} .2$ & $-13^{\circ} .0$ \\
1.4726 & 1.4529 & 1.4783 \\
3 hacim & 3 hacim & $3-4$ hacim \\
0.86 & 0.94 & 0.83 \\
16.56 & 17.53 & 16.83 \\
17.42 & 18.47 & 17.66
\end{tabular}

Değişik mevsimlerde ve farklı yerlerden toplanan yapraklardan elde edilen uçucu yağların gaz kromatogramı aşağıda verilmiştir (Krom. I).

Monoterpenik hidrokarbür fraksiyonunda 10 tane madde saptanmıştır. Bu maddelerin bağıl tutuş zamanları ve hidrokarbür fraksiyonunda bulunuş oranları Tablo II. de verilmiştir

Monoterpenik hidrokarbürlerin içerdiği maddelerden $\beta$ - pinen, sabinen ve limonen miktarları, Ankara çıkaklı fakat değişik zamanlarda toplanmış bitkilerden elde edilmiş yağlarda belirgin bir değişme, ilk ikisinde artış, limonende azalma göstermektedir. Bu değişiklik gaz kromatogramlarda da kolayca görülmektedir (Krom. 2). 
Nevin TANKER, Ayten DOĞAN, Bilge ŞENER

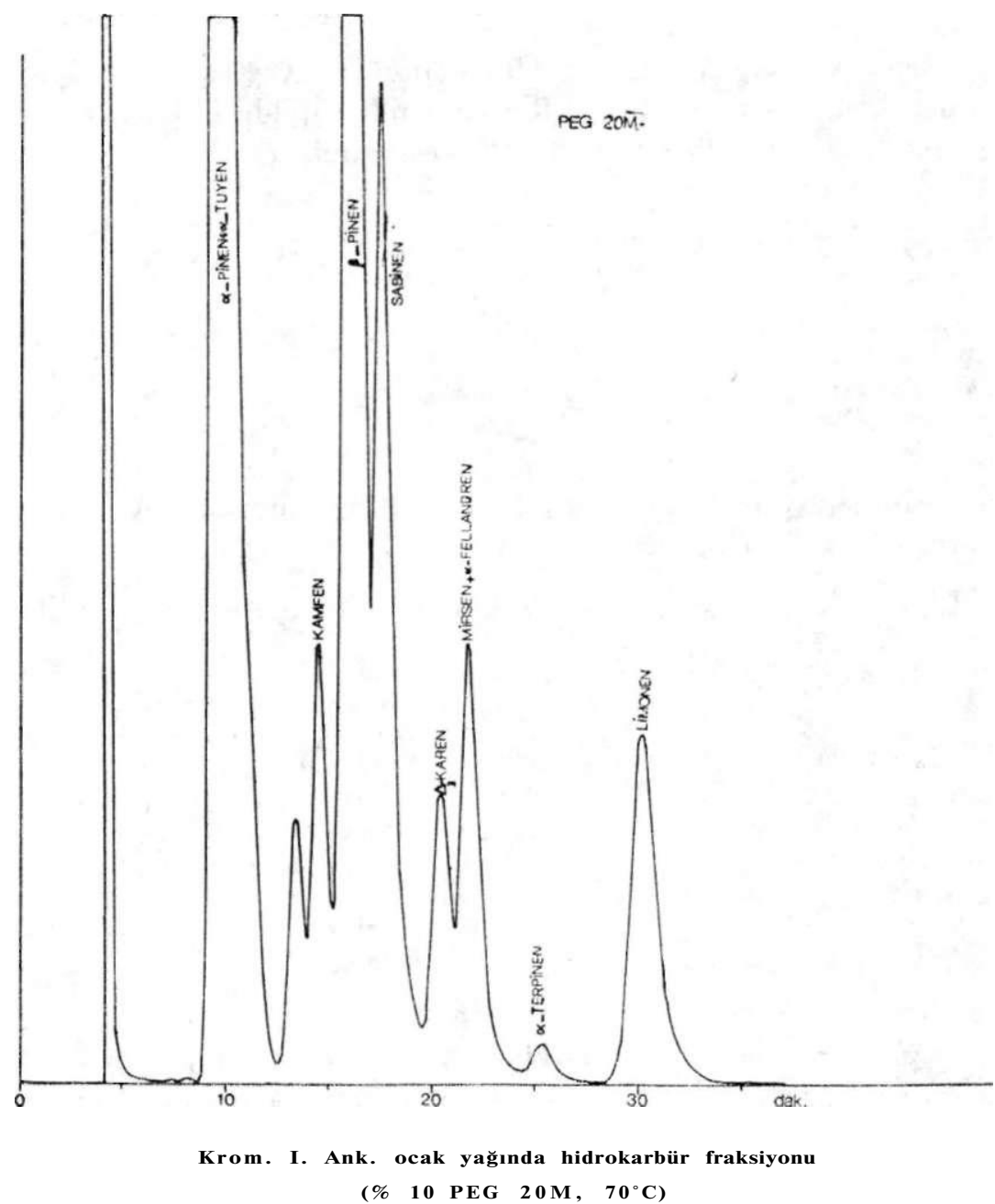

Aynı sistemde çalışarak fakat kolon 1 sısını $150^{\circ} \mathrm{C}$ ye yükseltilmesiyle elde edilen kromatogramda, Thuja orienatlis yapraklarının uçucu yağında, oksijenli bileşiklerden 10 tanesini saptayabildik (Krom. 3).

$\mathrm{Bu}$ bileşiklerin bağıl tutuş zamanları ile etil asetata geçen fraksiyonda \% bulunuş oranları aşağıdaki tabloda (III) gösterilmiştir. 
Thuja Orientalis L. Uçucu Yă̆ı

Tablo II. T. orientalis yapraklarının uçucu yağında bulunan monoterpenik hidrokarbürler

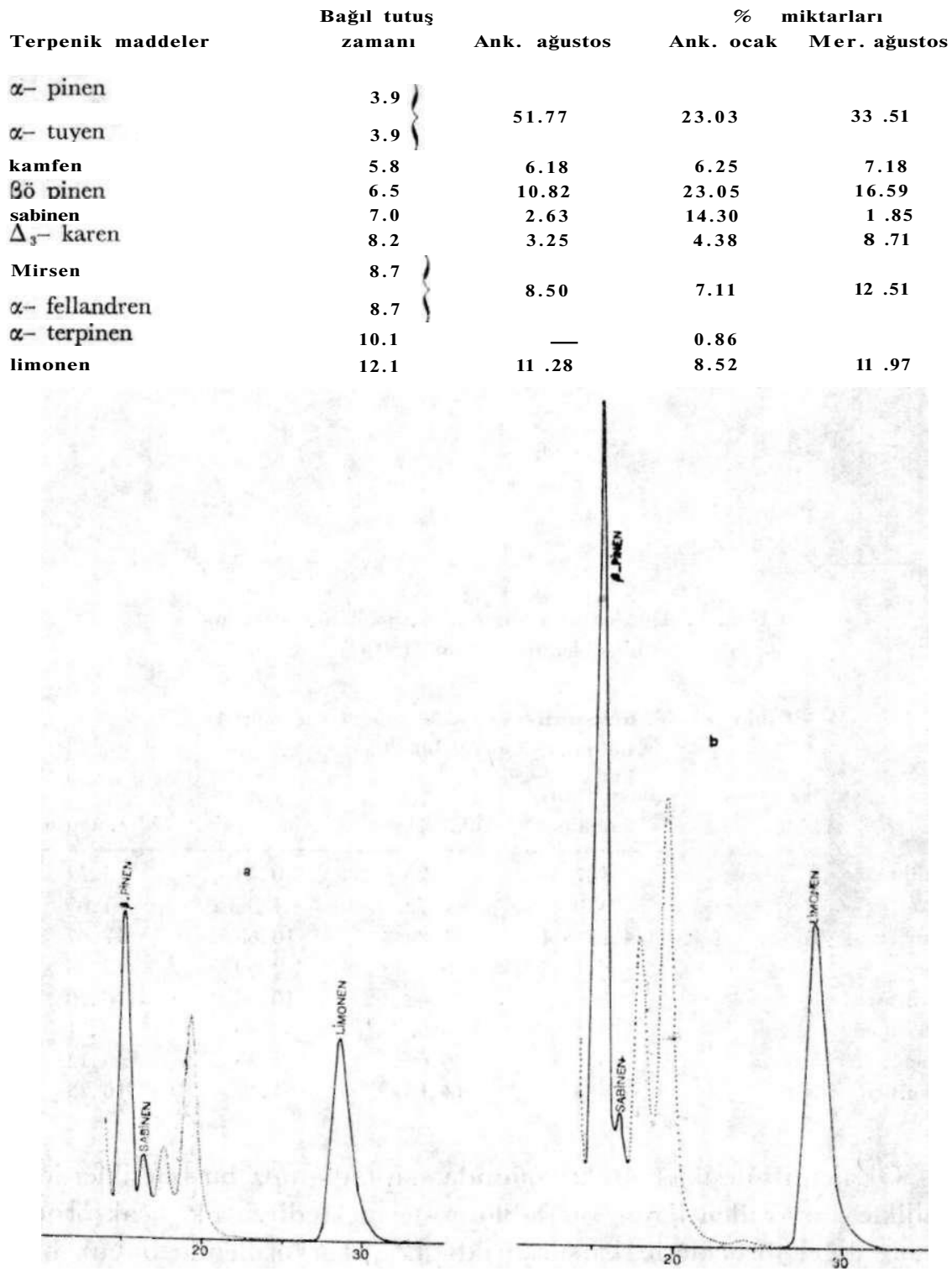

Krom. 2. Ank. ocak yağının (a) $\beta$ - pinen, sabinen ve limonen bakımından Arık. ağustos yă̆ı (b) ile karşılaştırılması 


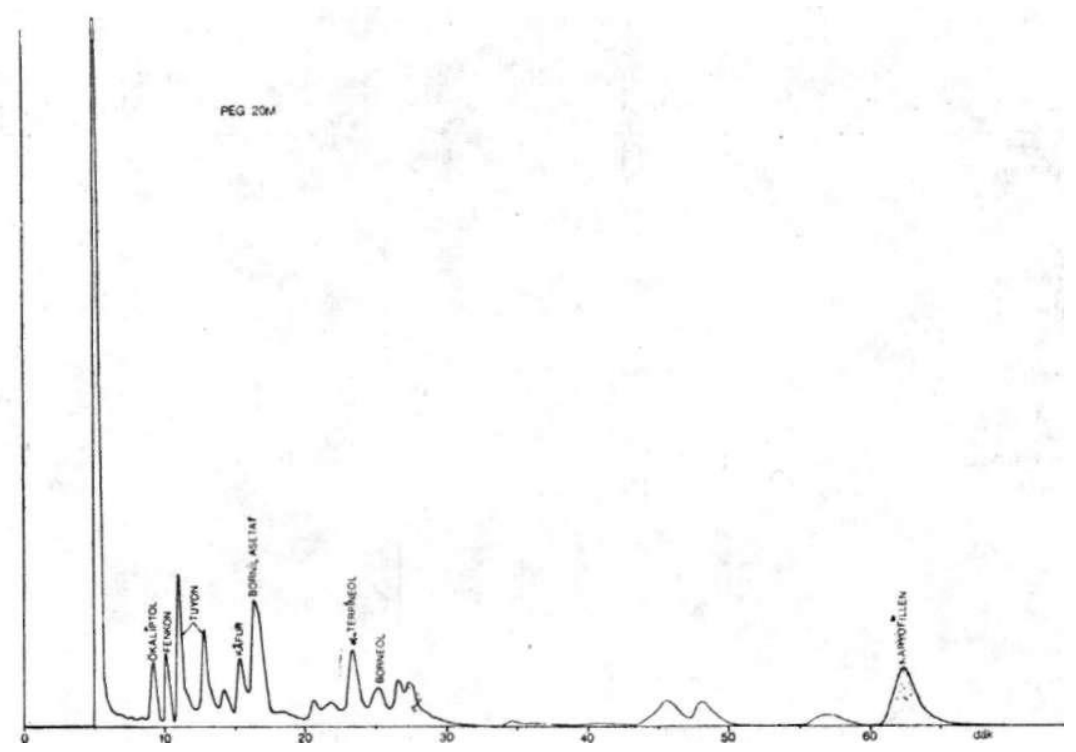

Krom. 3. Ank. ağustos yă̆ında oksijenli monoterpenik bileşikler fraksiyonu $\left(150^{\circ} \mathrm{C}\right)$

Tablo III. T. orientalis yapraklarının uçucu yağında bulunan oksijenli bileşikler

Bağıl tutuş

\section{Ökaliptol}

fenkor

tuyon $(\alpha+\beta)$

kâfur

bornil asetat

qterpilenol

borneol

karyofillen zamanı

\begin{tabular}{crrr} 
zamanı & Ank. ağustos & Ank. ocak & Mer.ă̆ustos \\
\hline 3.7 & 4.25 & 0.78 & 3.72 \\
4.0 & 4.72 & 1.55 & 4.65 \\
4.4 ve 5.1 & 21.23 & 10.88 & 17.67 \\
6.1 & 6.13 & 2.59 & 5.58 \\
6.6 & 14.62 & 10.36 & 16.28 \\
9.3 & 8.02 & -5.51 \\
10.1 & 5.66 & -15 & 5.12 \\
25.0 & 14.15 & 65.29 & 10.23
\end{tabular}

Oksijenli bileşikler fraksiyonunda saptadığımız bu bileşiklerden özellikle karyofillen ilginç bir tablo göstermektedir. Ank. ocak örneğimiz, diğer örneklerle karşılaştırıldığında, karyofillende büyük bir artışın varlığı göze çarpmaktadır. Bu karşılaştırmayı kromatogramlarla yapabiliriz (Krom. 4). 

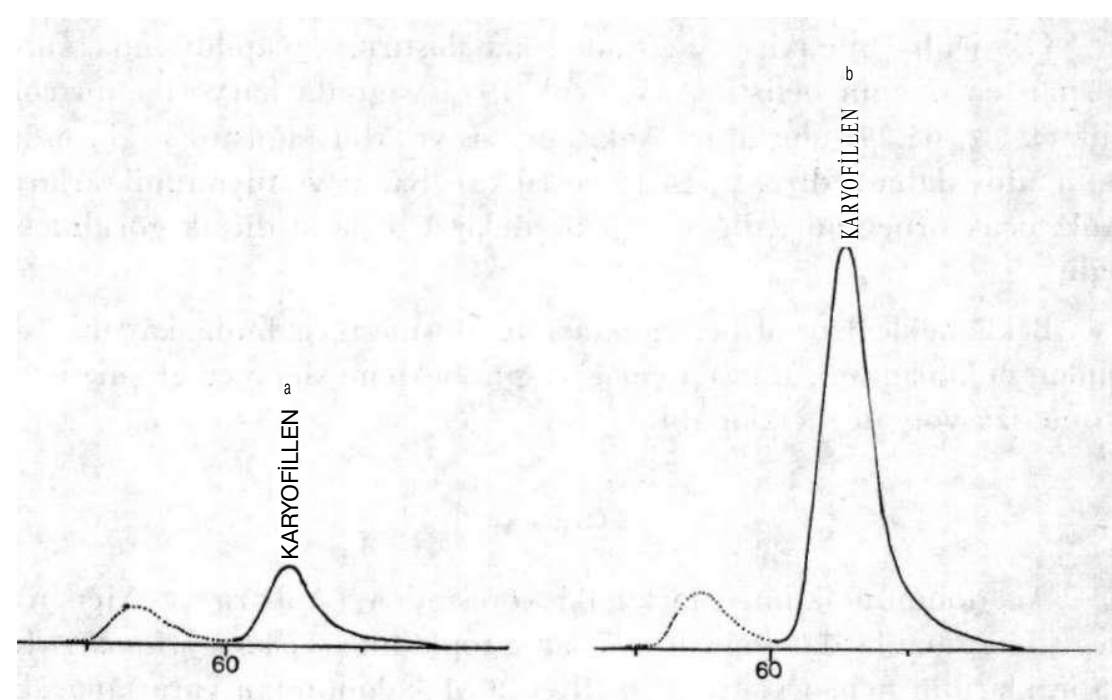

Krom. 4. Ank. ocak yağının (b) karyofillen bakımından Mer.

ağustos yă̆ı (a) ile karşılaştırılması

(Ank. ağustos Krom. 3 te yer almıştır)

TARTIŞMA ve SONUÇ

Görülüyor ki, 1974 te elde edilmiş uçucu yağ $\alpha$ - pinen, $\alpha$ - tuyen bakımından çok zengindir. Aynı zamanda toplanmış olmalarına karşın Mer. ağustos, Ank. ocak örnekleri arasında aynı maddeler açısından büyük ayrıcalık görülmektedir. Ancak, Ank. ağustos ve Ank. ocak arasında belirgin bir fark vardır.

Değişik mevsimlerde Ankara'dan toplanan örneklerdeki madde miktarı, kamfen, $\alpha$ - fellandren, $\Delta^{3}$ - karen-mirsen bakımından büyük farklılık göstermediği halde sabinen ve $\beta$ - pinen oranı büyük bir artış (sabinende \% 2.63 ten $14.30 \mathrm{a} ; \quad \beta$-pinende 10.8 den 23 e), limonen ise bir düşüş (\% 11.3 ten 8.5 e) göstermektedir.

$\mathrm{Bu}$ üç yağ, $\alpha$ - pinen - $\beta$ - pinen açısından karşılaştırıldı̆̆ında görülmektedir ki, taze distillenmiş ve az beklemiş yağlarda (Mer. ağustos 1975 ve Ank. ocak 1977) $\alpha$ - pinen oranı hemen hemen aynı $\beta$ - pinen oranı ise beklemiş yağlarda (Ank. 74) fazla görülmektedir. Bu iki yağın içerdiği (Mer. 75 ve Ank. 77) $\beta$ - pinen oranlarındaki farklılık mevsimden ileri gelebilir. 
Oksijenli bileşikler açısında karşılaştırma yapıldı̆̆ında göze çarpan en önemli belirti, Ank. ocak 1977 yağında karyofillenin çok yüksek (\% 65.29) oluşudur. Ank. ağustos ve Mer. ağustos yağlarında bu madde daha azdir. (\% 14.15 ve 10.23 ). Kâfur ve tuyon miktarları, Ank. ocak örneğinde, diğer örneklerdekinden daha düşük görülmektedir.

Beklemekle karyofillen miktarının düşmesi ve buna karşılık $\alpha$ pinen miktarının artması uçucu yağın beklemekle reçineleşmesi ve izomerizasyon ile açıklanabilir.

\section{ÖZ E T}

Anadolunun iklimce farklı iki yöresinden (Ankara ve Mersin), değişik zamanlarda (ağustos, ocak) toplanmış Thuja orientalis L. yapraklarının uçucu yağı \% 10 PEG $20 \mathrm{M}$ kolonundan yararlanarak, $70^{\circ} \mathrm{C}$ ve $150^{\circ} \mathrm{C}$ lerde, gaz-sivi kromatografisinde incelendi.

Ankara'da yetişen $T$. orientalis'te uçucu yă̆ miktarı (ocakta $\%$ 0.79, ağustosta \% 0.84), Mersin'de (daha sicak iklimde) yetişen bitkidekinden (\% 1.66) daha azdir.

Elimizde bulunan üç uçucu yağ örneği, Ankara ocak 1977 (I), Ankara ağustos 1974 (II) ve Mersin ağustos 1975 (III), silikagel üzerinde, n- pentan ile monoterpenik hidrokarbür ve oksijenli bileşiklerine ayrıldı. Monoterpenik hidrokarbür fraksiyonunda 10 madde saptand1. Bu maddeler ve (I) örneğindeki \% miktarları şöyledir: $\alpha$ - pinen ve $\alpha$ - tuyen karışımı (32.03), kamfen (6.25), $\beta$ - pinen (23.05), sabinen (14.30), $\Delta 3$ - karen (4.38), mirsen ve $\alpha$-fellandren karışımı (7.11), $\alpha$-terpinen (0.86) ve limonen (8.52). Görülüyor ki monoterpenik hidrokarbür fraksiyonunun büyük kısmını $\alpha$ - pinen, $\beta$ - pinen, sabinen ve limonen oluşturmaktadır. (II) ve (III) numaralı örnekler bu açıdan inclendiğinde: $\alpha$-pinen beklemiş yağda (II) en yüksek (\% 51.77), (III) te ise 33.51); $\beta$ - pinen bakımından en zengin (I), (II de \% 10.82, III te 16.59); sabinen (II) ve (III) örneklerinde çok az (\% 2.63 ve 1.85 ), bu örnekler limonen bakımından biraz zengin, (II) de \% 11.28, (III) te 11.97.

Oksijenli bileşiklerden saptadıklarımız, \% miktarları ile aşağıda verilmiştir. 
(I) örnekte ökaliptol (0.78), fenkon (1.55) ve kâfur (2.59) çok az, tuyon (10.88) (II de 21.23, II I te 17.67) gibi bornil asetat (10.36) ta (II) ve (III) tekinden (14.62 ve 16.28) düşük miktarlarda; $\alpha$ - terpineol ve borneol ise bu örnekte bulunmamaktadır. Bunlara karşın karyofillen çok yüksektir, \% 65.29 (II de 14.15, III te 10.23).

Ankara ocak 1977 örneğimiz (I), diğer örneklerden daha hafif kokuludur (kâfur, ökaliptol çok az), tuyonca zengin değildir, fakat karyofillen miktarı çok yüksektir. Ankara ağustos 1974, beklemiş örneğimiz (II) $\alpha$ ve $\beta$ tuyonca zengindir, Mersin'den toplanan ise bornil asetatı en yüksek oranda içermektedir.

\section{S U M M A R Y}

Volatile oil of the leaves of Thuja orientalis L. gathered from two climatically different districts of Anatolia (Ankara and Mersin) at different times (August, January), is assayed by gas-liquid chromatography using $10 \% \mathrm{PEG} 20 \mathrm{M}$ column at $70^{\circ} \mathrm{C}$ and $150^{\circ} \mathrm{C}$.

Thuja orientalis L. growing in Ankara contains $(0.79 \%$ in January, $0.84 \%$ in August), less volatile oil than the plants growing in Mersin (1.66 \%) which has a warmer climate.

Three volatile oil samples that we have, Ankara January 1977 (I), Ankara August 1974 (II), and Mersin August 1975 (III) are separated to their monoterpenic hydrocarbons and oxygenated compounds on silikagel by $n$-pentane, 10 compounds were detected in the monoterpenic hydrocarbons fraction. These compounds and their percentage in sample (I) are as follows:

A mixture of $\alpha$ - pinene and $\alpha$ - thujene (32.03), camphene (6.25), $\beta$-- pinene (23.05), sabinene (14.30), $\Delta^{3}$ - carene (4.38), a mixture of myrcene and $\alpha$-phellandrene (7.11), $\alpha$-terpinene $(0.86)$ and limonene (8.52). It is obvious that $\alpha$-pinene, $\beta$-pinene, sabinene and limonene form the larger part of monoterpenic hydrocarbon fraction. When samples (II) and (III) are assayed from this point of view: $\alpha$-pinene in the old oil (II) is the highest $(51.77 \%$; in (III), $33.51 \%)$; samples richest in $\beta$-pinene are (I), (10.82\% in II, 16.59 $\%$ in III); sabinene is very low in samples II and III $(2.63 \%$ and $1.85 \%)$. These samples are somewhat rich in limonene, $11.28 \%$ in II and $11.97 \%$ in I II. 
Oxygenated compounds which we detected and their $\%$ amounts are as follows:

In sample (I) eucalyptol (0.78), phencone (1.55) and camphor (2.59) are very low. Like thujone (10.88), (21.23 in II, 17.67 in III, bornyl acetate $(10.36)$ is also lower than the amounts in II and III (14.62 and 16.28); $\alpha$ - terpineole and borneol are not detected in this sample (I). On the other hand caryophyllene is very high, $65.29 \%$ (14.15 in II, 10.23 in III).

Our sample (I) Ankara January 1977, has less odour than other samples (camphor and eucalyptol are very low); (I) is not rich in thujone but caryophyllene is high. Ankara August 1974, old sample (II), is rich in thujone; sample (III) gathered from Mersin containes bornyl acetate in the highst percentage.

\section{I T E R A T Ü R}

1. Vashist, V. N., Nigam, M. C, Handa, K. L., and Gupta, G. N. - Indian Oil Soap J. 29 (2), 45 (1963).

2. Sakhatov, E., Belova, N. V. - Khim. Prir. Soedin. 3 (5), 349 (1967), Ref: C. A. 68, 16064 p.

3. Hirose, Y., Nakatsaka, T.,- Mokuzai Gakkaishi, 4, 26-9 (1968), Ref: C. A. 52, 11362 e.

4. Nasır -ud- Din Zahid and Go. Pakistan J. Sci. Ind. Res. 6, 260-2 (1963), Ref: G.A. 63,18491 h.

5. Sakhatov, E., Belova, N. V., - Farmatsiya (Moskow). 17 (3), 33, (1968) Ref: C. A. 69,542502 .

6. Guenther, E. - The Essential Oils, Volume VI, D. Van Nostrand Company, Inc. New York (1952).

7. Tanker, N. - J. Fac. Pharm. Ankara 3, 112 (1973).

8. Tanker, N. - J. Fac. Pharm. Ankara 5, 171 (1975). 